\title{
More than dead males: reconstructing the ontogenetic series of terrestrial non-biting midges from the Eocene amber forest
}

\author{
Viktor Baranov, Christel Hoffeins, Hans-Werner Hoffeins \& Joachim T. Haug
}

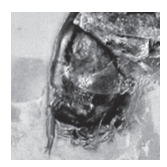

\begin{abstract}
Chironomidae (non-biting midges) is a very diverse group of Diptera. While most non-biting midges have aquatic larvae, some lineages have evolved terrestrial larvae. Here we report the first record of the larva of a non-biting midge from Baltic amber. The overall morphology of the specimen is indicative of an originally terrestrial habitat of the larva. This is based on the absence of setae on the body, absence of prominent anal papillae, a single anterior parapod and small posterior parapods. The larva can be identified as a representative of the group (genus) Bryophaenocladius. Adults of this group are already known from the same deposit. An exuvium of a pupa, most likely also closely related to this group, is known from contemporary Rovno amber. This allows to reconstruct the post-embryonic ontogeny, at least on a phase level, for a fossil representative of Diptera based on well preserved specimens in amber for the first time. The current study provides crucial insight into the evolution of terrestrialisation of larval forms within Chironomidae. Key words: Diptera, Chironomidae, Amber, Eocene, larvae, pupa, adult, Insecta, ontogeny, Eocene.
\end{abstract}

Baranov, V., Hoffeins, C., Hoffeins, H.-W., \& Haug, J.T. 2019. More than dead males: reconstructing the ontogenetic series of terrestrial non-biting midges from the Eocene amber forest. Bulletin of Geosciences 94(2), 187-199 (9 figures). Czech Geological Survey, Prague. ISSN 1214-1119. Manuscript received January 6, 2019; accepted in revised form March 15, 2019; published online May 6, 2019; issued June 17, 2019.

Viktor Baranov, Department of Biology II, LMU Munich, Großhaderner Str. 2, 82152, Planegg-Martinsried, Germany; baranowiktor@gmail.com •Christel Hoffeins \& Hans-Werner Hoffeins, Liseistieg 10, D-22149 Hamburg, Germany • Joachim T. Haug, Department of Biology II \& GeoBio-Center, LMU Munich, Großhaderner Str. 2, 82152, Planegg-Martinsried, Germany

Holometabola is a superdiverse ingroup of Insecta. Most of the diversity within Holometabola results from only four hyperdiverse lineages, one of which is Diptera. Nonbiting midges (Chironomidae) have been considered to be among the most successful ingroups of Diptera in the history of the group (Marshall 2012). There are at least 6300 formally described extant species of Chironomidae. Their larvae have colonized most of the available freshwater habitats, as well as some marine, sub-terrain and terrestrial habitats (Langton 1995, Ferrington 2008, Andersen et al. 2016). Terrestrial larvae of Chironomidae are important for our understanding of the physiology and evolutionary biology of the group. The reason for that lies in the habitation of the larvae in non-aquatic habitats, such as wet soil, dung, leaf-litter, moss carpets etc., which is generally considered to be a secondary specialisation for the group (Langton 1995, Delettre 2005). Therefore, for long, terrestrial larvae of Chironomidae have been considered as models for desiccation adaptation, osmoregulation and cryptobiosis (Frouz 1997, 2010; Wichard et al. 2002). In extant ecosystems representatives of Chironomidae with terrestrial larvae are most common in areas with tropical or moderate climate and high saturation of the air with water vapor (Andersen et al. 2015, 2016; Zelentsov et al. 2012). The fossil record is usually devoid of terrestrial larvae of Chironomidae, as these are not normally found in the areas of the active sedimentation (i.e. lake basins, river deltas; e.g. Wichard et al. 2009). Nevertheless, some amber deposits have a rather high proportion of adult non-biting midges that should possess terrestrial larvae, based on phylogenetic reasoning (Zelentsov et al. 2012). In Rovno amber in particular, the share of such adult morphotypes of Chironomidae reaches 40.1\% (Zelentsov et al. 2012). Such morphotypes are also relatively abundant in Baltic and Bitterfeld (Saxonian) ambers (Hoffeins \& Hoffeins 2003, Seredszus \& Wichard 2007). Giving the abundance of these adult morphotypes, we should expect to find corresponding immature stages, hence terrestrial larval representatives of Chironomidae in Eocene amber deposits (Zelentsov et al. 2012). Such a probability is even increasing due to the relatively high abundance of bryophytes, which serve as a substrate for modern terrestrial larvae of Chironomidae, in amber (Weitschat \& Wichard 2010). Indeed, Andersen et al. (2015) reported the exuvia of a pupa of Chironomidae from Rovno amber, more precisely a possible representative 
of Bryophaenocladius Thienemann, 1934. This specimen shows all traits known from pupae of extant representatives of Chironomidae with terrestrial larvae, such as: 1) reduced anal papillae; 2) reduced setation of the abdominal segments; 3) absence of thoracic horns; and 4) presence of small, strong hooks on the tergites, helping pupae to navigate their substrates (Langton 1995, Glime 2017).

Here we present the first record of a larva of Chironomidae from amber. This larva is comparable to those of modern representatives of Bryophaenocladius. As the only known pupa of Chironomidae in amber is from the same group (genus), we can now reconstruct all major phases of the post-embryonic ontogenetic sequence of a morphotype of Chironomidae with terrestrial larvae based on actual fossils. This provides important insights into the evolution of terrestrial larvae of Chironomidae and changes in the individual development (or lack of thereof) in deep time.

\section{Materials and methods}

Material. - The amber was obtained from a commercial source in Yantarnyj, Kaliningrad District (formerly Palmnicken, Königsberg) in 2005. Currently it is part of the collection of C. and H.W. Hoffeins collection number CCHH \#1519-9 and will be deposited at the Senckenberg Deutsches Entomologisches Institut (SDEI) with inventory number: Dip-00607.

The amber piece is embedded in polyester resin (Hoffeins 2001). A syninclusion, a single springtail
(Collembola), is apparent. For comparative purposes, we used extant terrestrial larvae of Chironomidae, namely those of Bryophaenocladius furcatus (Kieffer, 1916) [in Tienemann \& Kieffer (1916)] and B. tirolensis (Goetghebuer, 1938). These are part of the slide mounted collection of Chironomidae of the Zoologische Staatssammlung München (ZSM), Munich, Germany (without repository number). We compared the (adult) holotype of the fossil species Bryophaenocladius circumclusus Seredszus \& Wichard, 2007 with the other specimens from the same collection.

In addition to that, we have (re-)examined the single specimen of a fossil pupa of Chironomidae cf. Bryophaenocladius (Andersen et al. 2015) deposited in the Schmalhausen Institue of Zoology (Kiev, Ukraine) and the fossil adult Bryophaenocladius beuki Baranov, Andersen and Hagenlund, 2015 deposited in Maastricht Natural History Museum (Maastricht, Netherlands). Morphological terminology largely follows Sæther (1980), yet attempting to be understandable to non-experts as well as providing a frame to the general organisation of Euarthropoda.

Imaging methods. - Specimens in focus were imaged using a Keyence VHX-6000 Digital microscope, with ring light type illumination and cross-polarised co-axial illumination. All photos presented in this paper are composite images. Images were assembled using panorama functions to overcome limitation of field of view under higher magnifications. Each image detail was recorded by a stack of images of shifting focus to overcome limitation of depth of field (Haug et al. 2008, 2011, 2013a). Fusion

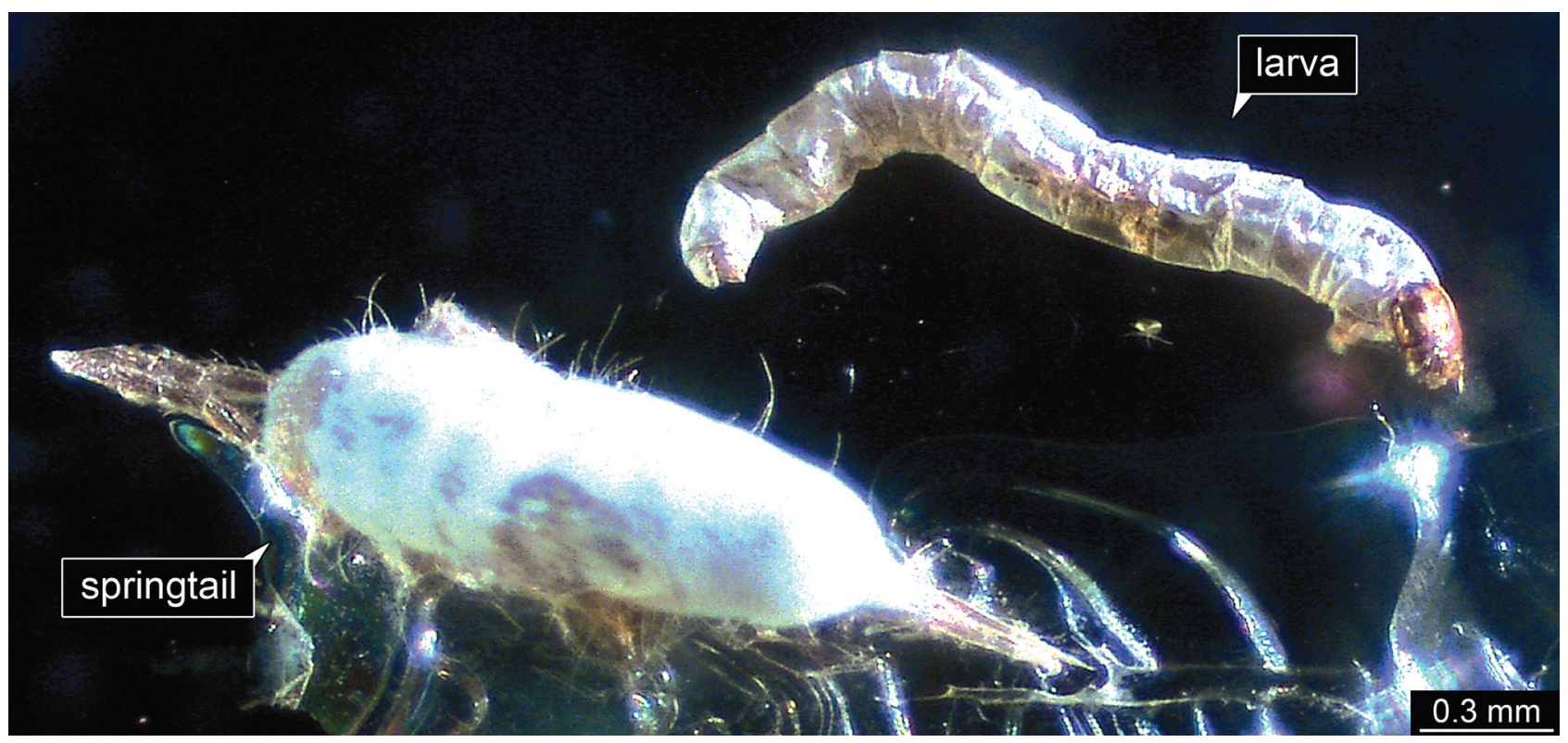

Figure 1. Larva of cf. Bryophaenocladius with syninclusion of Collembola. 


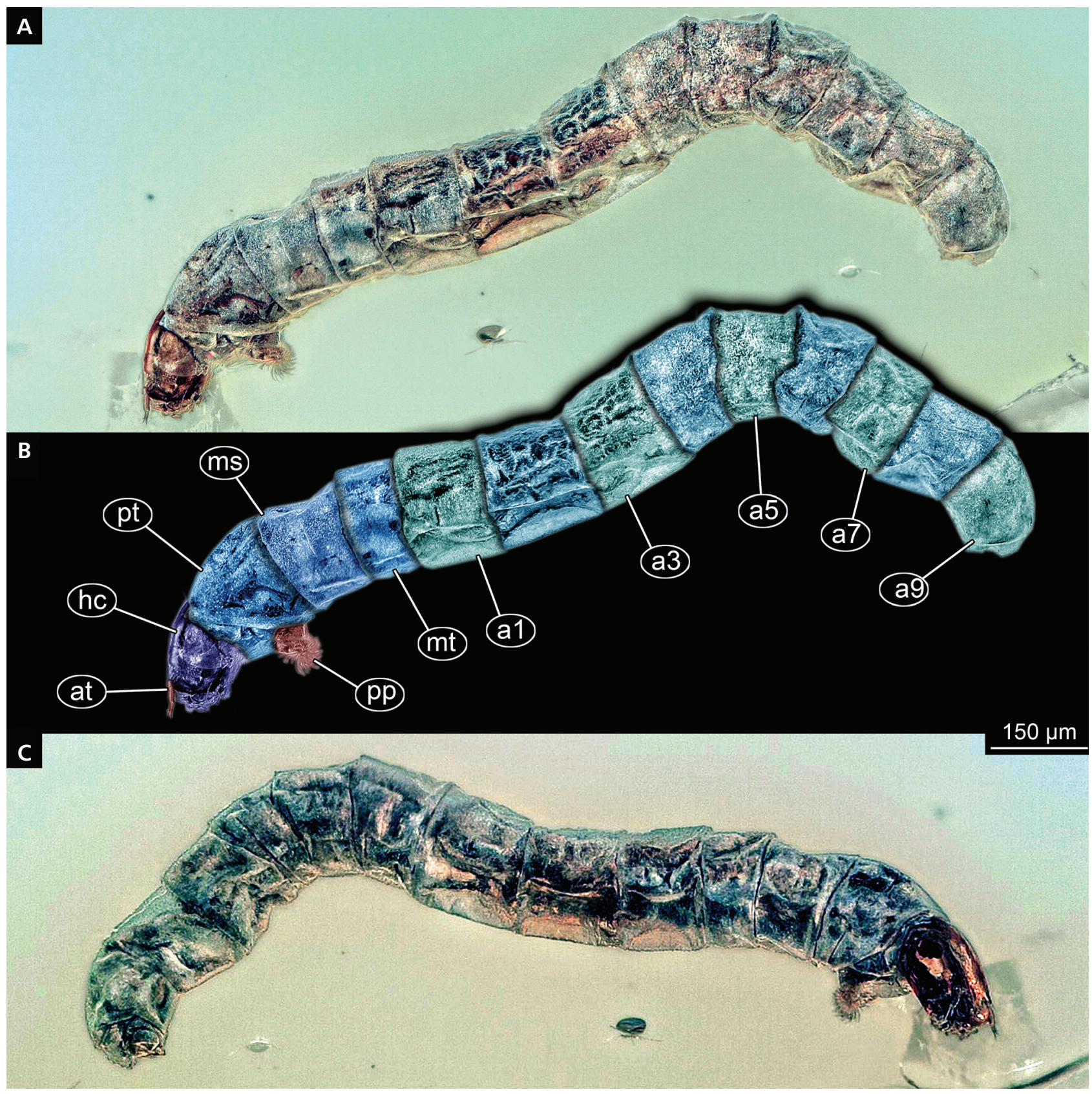

Figure 2. Larva cf. Bryophaenocladius; A - ventro-lateral view; B - ventro-lateral view (marked); C - dorso-lateral view. Abbreviations: at - antennae; hc - head capsule; pt - prothorax; ms - mesothroax; $\mathrm{mt}$ - metathorax; pp - parapod (anterior); a1-a9 - abdominal segments 1-9.

into sharp images and panorama stitching was performed with the built-in software. We also employed the HDR function included in the Keyence microscope software; therefore, every single frame is a composite from several images taken under different exposure times (Haug et al. 2013b, 2018). Images of extant larvae of Chironomidae were taken using a DCM 510 ocular camera (Haug et al. 2013a) and Leitz Diaplan optical microscope. Stacks were processed with Combine ZM. Optimisation of all images was performed in Photoshop CS2.
Details on imaging of the pupal exuvia of Chironomidae cf. Bryophaenocladius and B. beuki are re-used with permission from Andersen et al. (2015) and Baranov et al. (2015a), respectively.

\section{Results - description of specimen}

General. - Small sized, roughly worm-like animal (Figs $1 ; 2 \mathrm{~A}-\mathrm{C})$. Total length $1.73 \mathrm{~mm}$. Body distinctly organised 

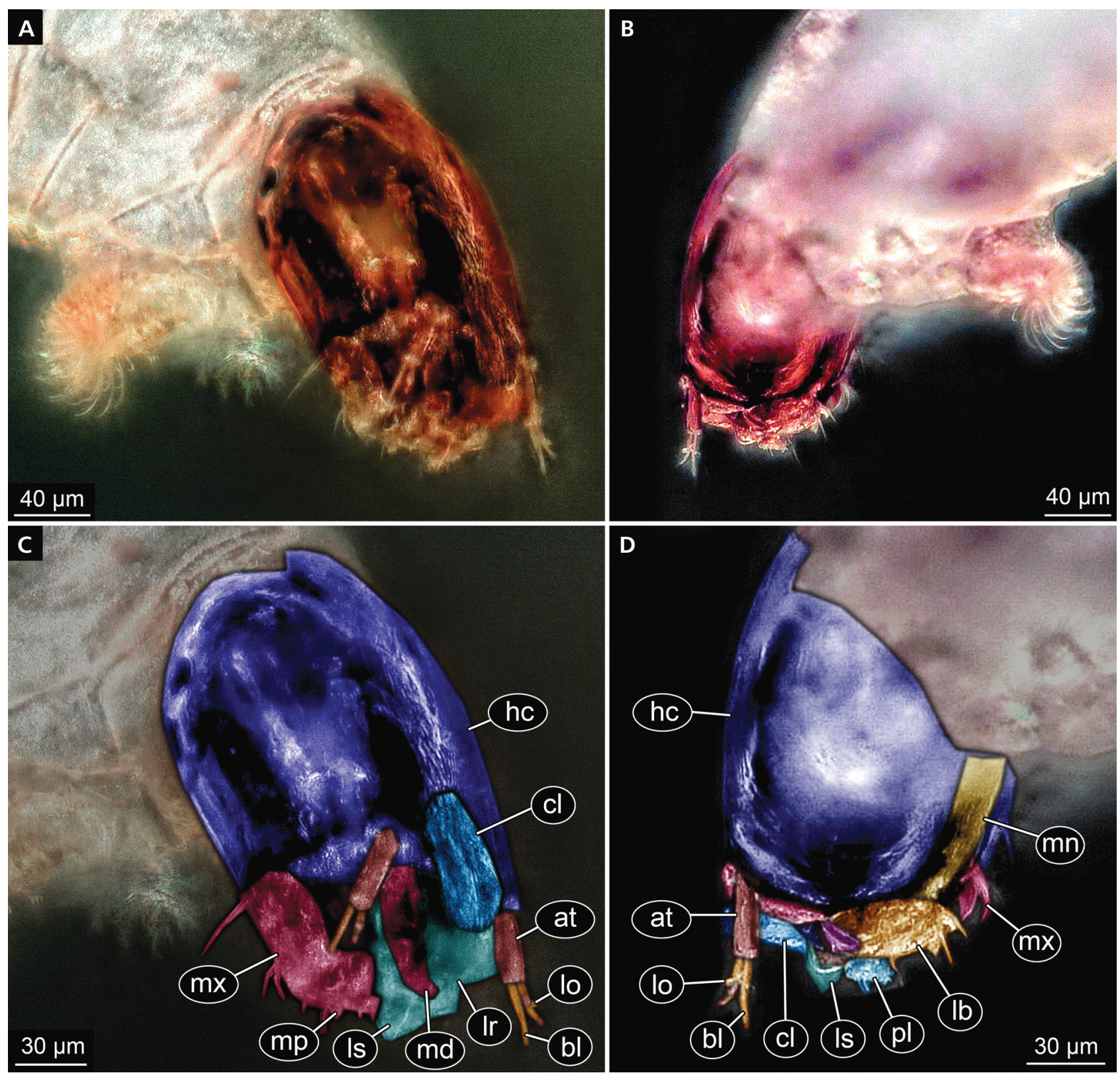

Figure 3. Larva cf. Bryophaenocladius; A - head, dorso-lateral view; B - head, ventro-lateral view; C - head, dorso-lateral view, with marked structures; D - head, ventro-lateral view, with marked structures. Abbreviations: hc - head capsule; at - antenna; bl - blade of antenna; cl - clypear sclerite; lr - labrum; lo - Lauterborn organs; md - mandible; mx - maxilla; mp - maxilla palpi; mn - mentum; pl - pecten labralis; ls - labral setae 2.

into head and segmented trunk. Accessible only in lateral aspects, yet on both sides.

Head. - Capsule distinct, oval in lateral view, $170 \mu \mathrm{m}$ long (Fig. 3A-D). Six segments contributing to head, ocular segment and post-ocular segments $1-5$. Surface of head capsule smooth, stemmata (larval eyes) could not be recognized. A number of black spots, which do not appear to be stemmata, are present on the lateral sides of the head capsule ("genal" sclerites; Fig. 3C). Further structures of ocular segment apparent: clypeus (clypear sclerite) elongated, oval in general shape; labrum small but recognisable, with S1 and S2 labral setae, simple, S2 very prominent (Fig. 3D). Pecten labralis present (possibly group of sclerotised setae; Fig. 3D).

Antennae. - (appendages of post-ocular segment 1) inserted dorsally at the proximal region of labrum. Antennae $50 \mu \mathrm{m}$ long, with 5 main elements. Element 1 large, $28 \mu \mathrm{m}$ long. So-called "blade"-structure inserting at the top of second element. Large "Lauterborn" organs on the top of second element (Fig. 3C, D). Second post- 
ocular segment (intercalary segment) without externally recognisable structures.

Premandible present, small. Mandibles elongated, with several teeth (appendages of post-ocular segment 3 ).

Maxilla (appendages of post-ocular segment 4), recognisable by distal parts, palps. Maxillary palp is stump-like, appears largely reduced (Fig. 3D). Labium (appendages of post-ocular segment 5) recognisable by proximal part, mentum. Mentum poorly visible, seemingly bearing several lateral teeth in addition to the central, wider tooth.

Trunk. - Trunk tube-shaped, cylindrical, diameter largely constant along trunk and larger than that of the head capsule. Trunk with 14 visible segments -3 thoracic segments and 10 abdominal segments (Figs 2A-C; 4A, B). Thoracic segment 1 (prothorax) slightly shorter than head capsule, about as long as high (diameter) bearing distinct parapod ventrally forming single ridge-shaped structure, bearing numerous translucent claws (Figs 2A-C; 4A, B). Thoracic segment 2 (mesothorax) shorter than preceding segment. Thoracic segment 3 (metathorax) even shorter, shortest trunk segment. Trunk segments only with very weak indication of distinct dorsal sclerites, i.e. tergites. Abdominal segments without notable setation. Segments with a more pronounced differentiation of sclerites, i.e. tergites and sternites. Abdominal segments 1-3 sub-similar, each longer than metathorax, about as long as prothorax. Abdominal segment 4 most likely of the same length as preceding segment, yet partly squeezed ventrally due to the posture of the specimen. Abdominal segments 5-9 appear sub-similar, each slightly shorter than preceding segments. Abdominal segment 10 or trunk end possible a compound structure of abdominal segments 10, 11 . With numerous structures: Procerci (anal setae-bearing pedestals on the abdominal tergite 9) absent (Fig. 4A). Paired posterior parapods, bearing small claws and small anal tubes present (Fig. 4A, B).

\section{Discussion}

\section{Larval morphology}

The new larva from Baltic amber is clearly a representative of Chironomidae, as it possesses prognathous mouthparts, paired posterior parapods in combination with the absence of spiracles (Ekrem et al. 2017; Figs 1; 2A-C; 3A-D; 4A, B). These traits allow us to exclude affinities of the new larvae with ingroups of Chironomidae other than Orthocladiinae:

1) The larva has non-retractable antennae, which clearly separates it from larvae of Tanypodinae.

2) The absence of "ventromental" plates at the sides of the ventromentum separates it from larvae of Chironominae and Prodiamesinae (Cranston 1995; Fig. $3 \mathrm{~A}-\mathrm{D})$.

3) A toothed mentum and a body not covered in strong
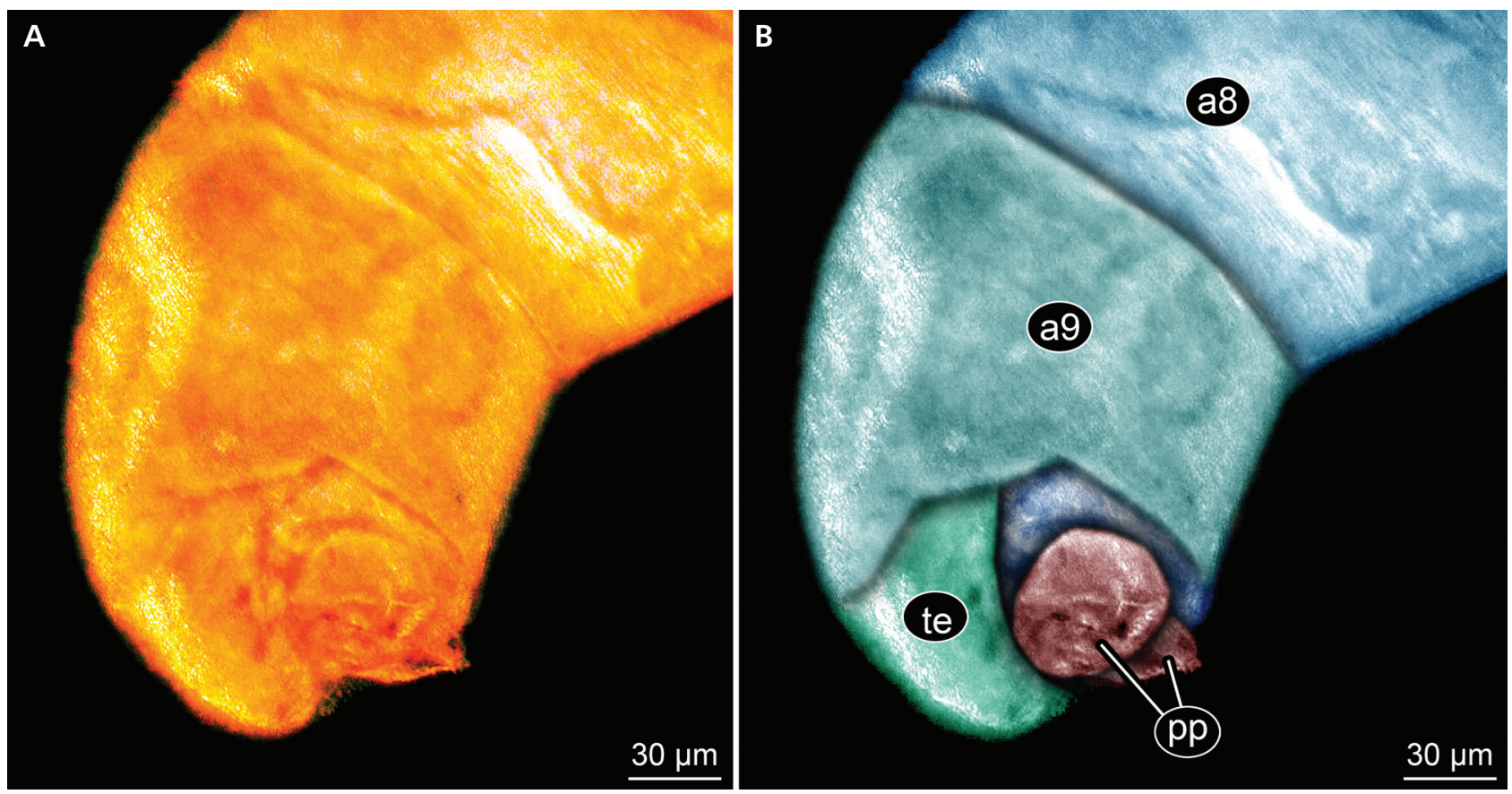

Figure 4. Larva cf. Bryophaenocladius, rear end of the abdomen A - unmarked; B - marked. Abbreviations: pp - parapod (posterior); a8, a9-abdominal segments 8 and 9; te - trunk end, possibly segments $10+11$. 

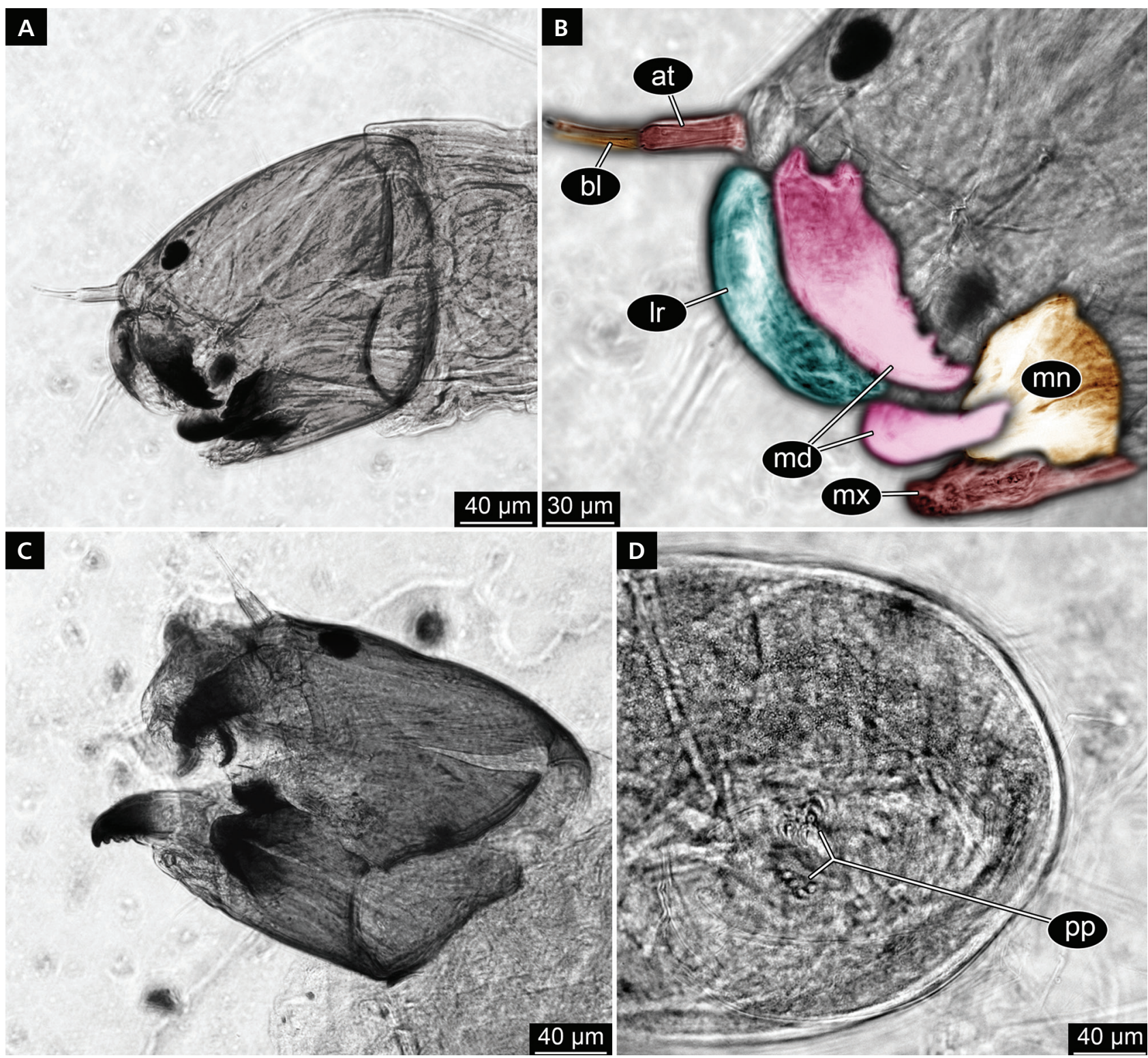

Figure 5. A, B, D - Bryophaenocladius furcatus; A - head capsule, ventral view. Voucher specimen from collection of the ZSM; B - marked anterior edge of the head capsule. Same specimen as in Fig. 5A; D - segments VIII and IX of the abdomen. Same specimen as in Fig. 5A, B. Voucher specimen from collection of the ZSM. - C - Bryophaenocladius tirolensis, head capsule, ventral view. Abbreviations: at - antenna; bl - blade of antenna; lr - labrum; $\mathrm{mx}$ - maxilla; $\mathrm{mn}$ - mentum; $\mathrm{md}$ - mandible; pp - parapod (posterior).

setae/tubules are separating the new larvae from those of Aphroteniinae (Cranston 1995; Figs 2A-C; 3B, D).

4) The presence of premandibles is excluding affiliations of the new larva with Podonominae or Buchonomyiinae (Cranston 1995; Fig. 3D).

5) The fossil larva possesses a non-annulated third element of the antenna, which, together with a non-elongated postoccipital margin of the head capsule, separates it from larvae of Diamesinae (Cranston 1995; Fig. 3D).

Based on its morphology, the new larva therefore fits only well within Orthocladiinae ("subfamily"; Cranston 1995).
We have refrained here from the formal description of the larval specimen as a separate species, due to possible synonymy (see discussion on the Bryophaenocladius morphotype). Yet, the specimen can be relatively confidently identified as a representative of the group (genus) Bryophaenocladius based on the following combination of characters: small-sized larva; S1 and S2 setae of the labrum simple; antennae with 5 elements; trunk smooth, lacking setae; single anterior parapod; paired posterior parapods; procerci (setae pedestals on the abdominal segment 9) and anal setae absent; anal papillae small (Wiederholm 1983, Andersen et al. 2015). 


\section{Morpho-ecological specialisations of the larva to a terrestrial habitat}

Terrestrial larvae of Chironomidae are all characterized by a series of similar morphological traits (Frouz 2010; Fig. 5A-D). The majority of terrestrial larvae have shortened anterior and posterior parapods, often only a single parapod is present, or parapods are absent altogether (Andersen et al. 2013; Fig. 4A, B). The new larva from Baltic amber has only a single, ridge-like anterior parapod, bearing numerous claws (Fig. 4A, B). The posterior parapods of the larva are represented by two quite short protrusions from abdominal segment 9, each of which is bearing a set of claws (Fig. 4A, B).

The anal papillae on abdominal segment 9 are greatly reduced, as is the case for many extant terrestrial larvae of Chironomidae (Langton 1995; Figs 4A, B; 6A). Anal papillae are most probably serving as an osmoregulation organ (Komnick \& Wichard 1975). Since terrestrial larvae only spend part of their time in hypo-osmotic aquatic environments, they do not need such organs (Frouz 2010, Langton 1995). In addition to the reduced parapods and anal papillae, the fossil larva has an almost naked body, lacking setae and other ornamentation. This is another characteristic trait of many terrestrial larvae of Chironomidae (Frouz 2010; Fig. 6A). The general body shape of terrestrial larvae of Chironomidae, including the one from Baltic amber, is characterised by the higher height to length ratio of the abdominal segments in contrast to the ration in many aquatic larvae (Langton 1995; Fig. 6A, B).
The morphology of the larvae indicates a terrestrial habitat, probably associated with bryophytes (Langton 1995), which apparently was relatively abundant in the Baltic amber forest (Weitschat \& Wichard 2010). This is further supported by the presence of a spring tail as a syninclusion (Fig. 1). We therefore now have a strong indication that terrestrial larvae of Chironomidae were present at least 38 mya (Priabonian).

\section{A reconstructed ontogenetic sequence of a chironomid based on amber fossils}

The discovery of the new larva from Baltic amber allows us for the first time to reconstruct an ontogenetic sequence for a "terrestrial morphotype" of Diptera using material from amber (Andersen et al. 2015, Kirk-Spriggs \& Muller 2017). There are already some instances of circumstantial association of different aquatic life stages of dipterans based on compression fossils (Kalugina \& Kovalev 1985). Yet, this is the first case in which all the life phases (Fig. 7) of a dipteran morphotype with terrestrial larvae as well preserved specimens from amber are available (Wichard et al. 2009).

\section{Bryophaenocladius morphotype}

Bryophaenocladius is a large monophyletic ingroup of Chironomidae known from Baltic (Priabonian of Eocene) and New Zealand (Chattian of Miocene)
Figure 6. Schematic body structure of aquatic (A) and terrestrial (B) larvae of Chironomidae.

\section{aquatic larva}
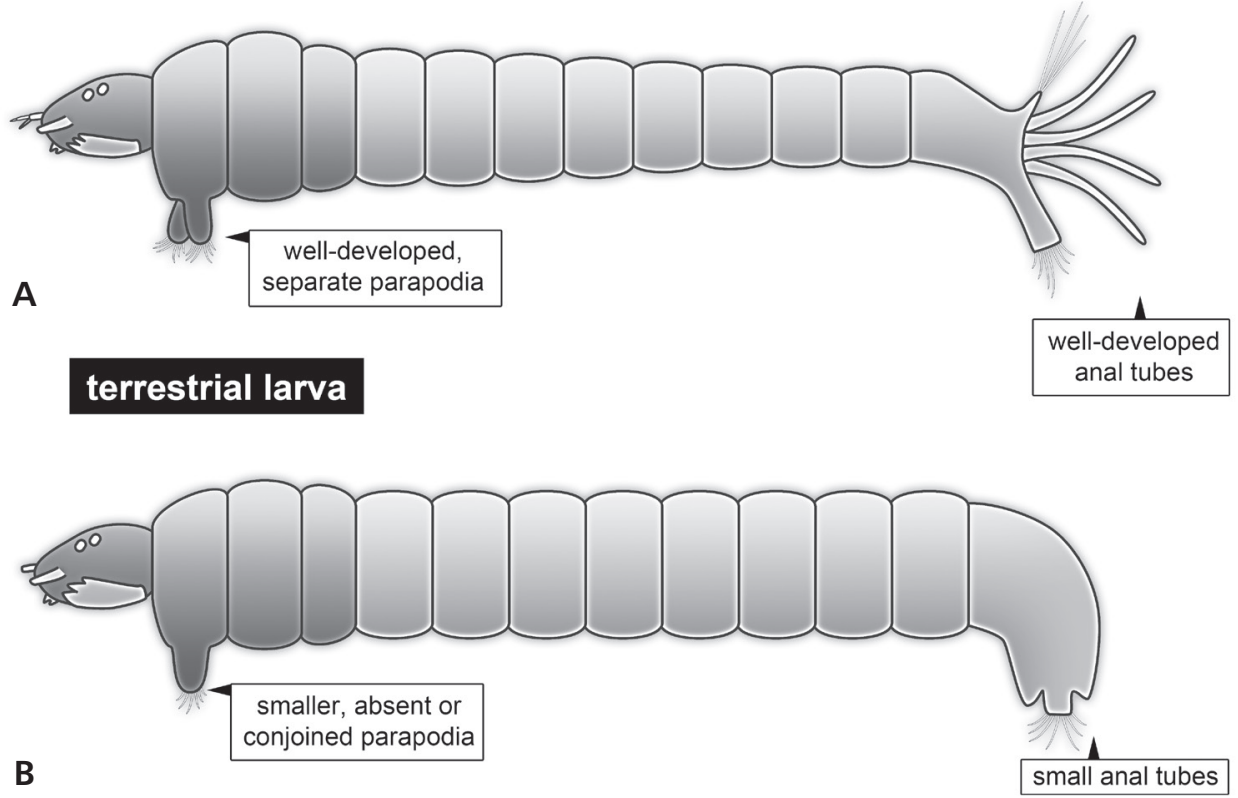
amber and with a (probably) cosmopolitan modern day distribution (Ashe \& O'Connor 2012). There are over 100 extant species of Bryophaenocladius. Their larvae live in very different habitats from fast flowing streams to salt marshes (Andersen et al. 2013). Many of the extant species of Bryophaenocladius have factually terrestrial larvae developing in wet mosses. This was also the reason for the initial name of the group Bryophaenocladius [from 'bryophyte', Greek ( $\beta$ póov) Bryon, tree-moss]. Due to the terrestrial mode of life, most larvae of the group Bryophaenocladius possess a combination of the morphological traits described above for terrestrial larvae of Chironomidae (Langton 1995, Gilme 2017).

Pupa stages of Bryophaenocladius are likewise characterized by a number of specialisations. Pupae of Bryophaenocladius have reduced (absent) thoracic horns; these respiratory organs are useless in terrestrial environments (Wiederholm 1986, Langton 1995). They are also characterized by the absence of frontal and ocular setae (these setae are playing a sensory role in aquatic pupae), presences of the strong "shagreen"-like ornamentation on abdominal tergites (used to anchor

\section{Ontogenetic sequence of fossil non-biting midges}

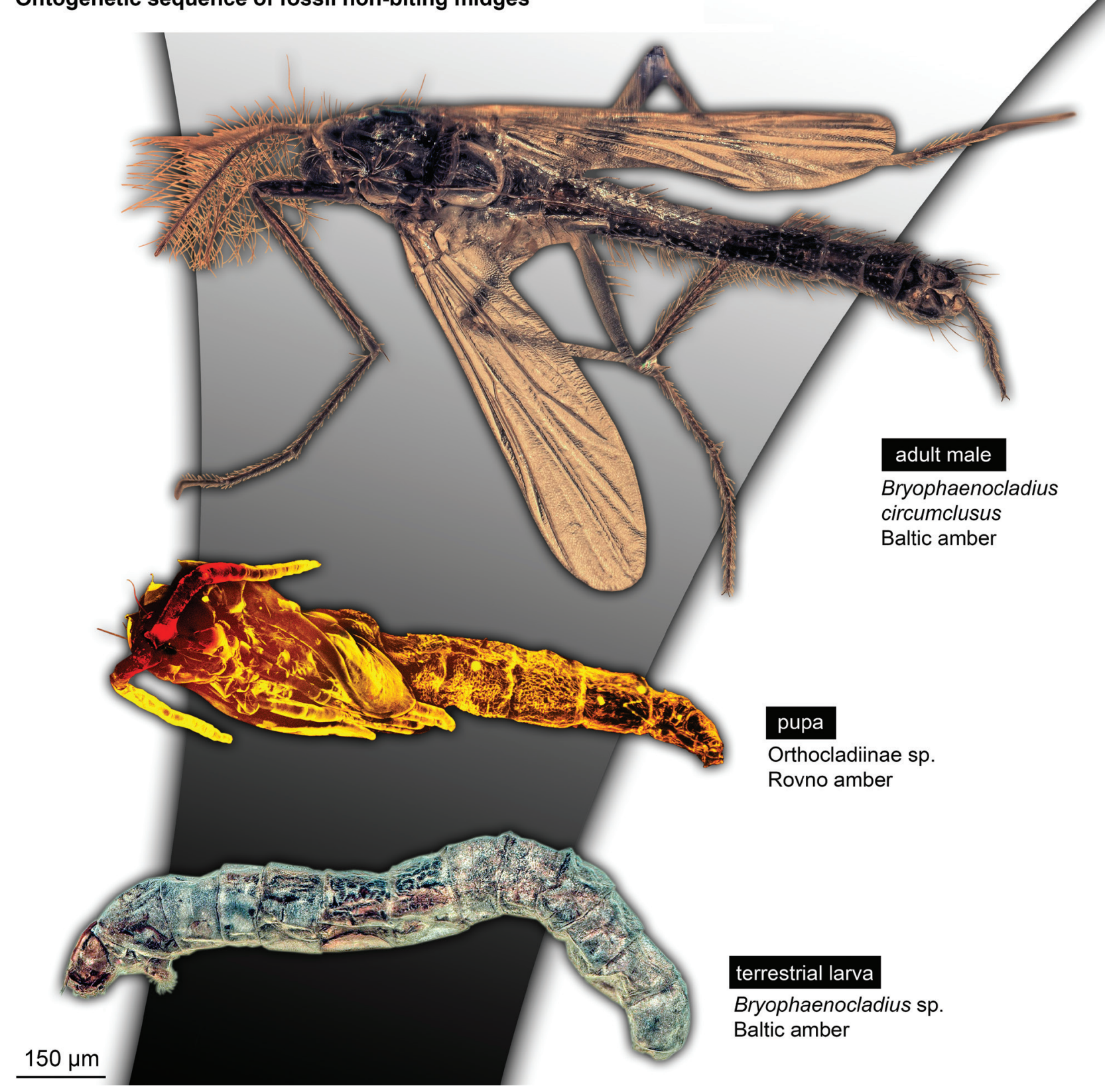

Figure 7. Reconstructed ontogenetic sequence of Bryophaenocladius. 


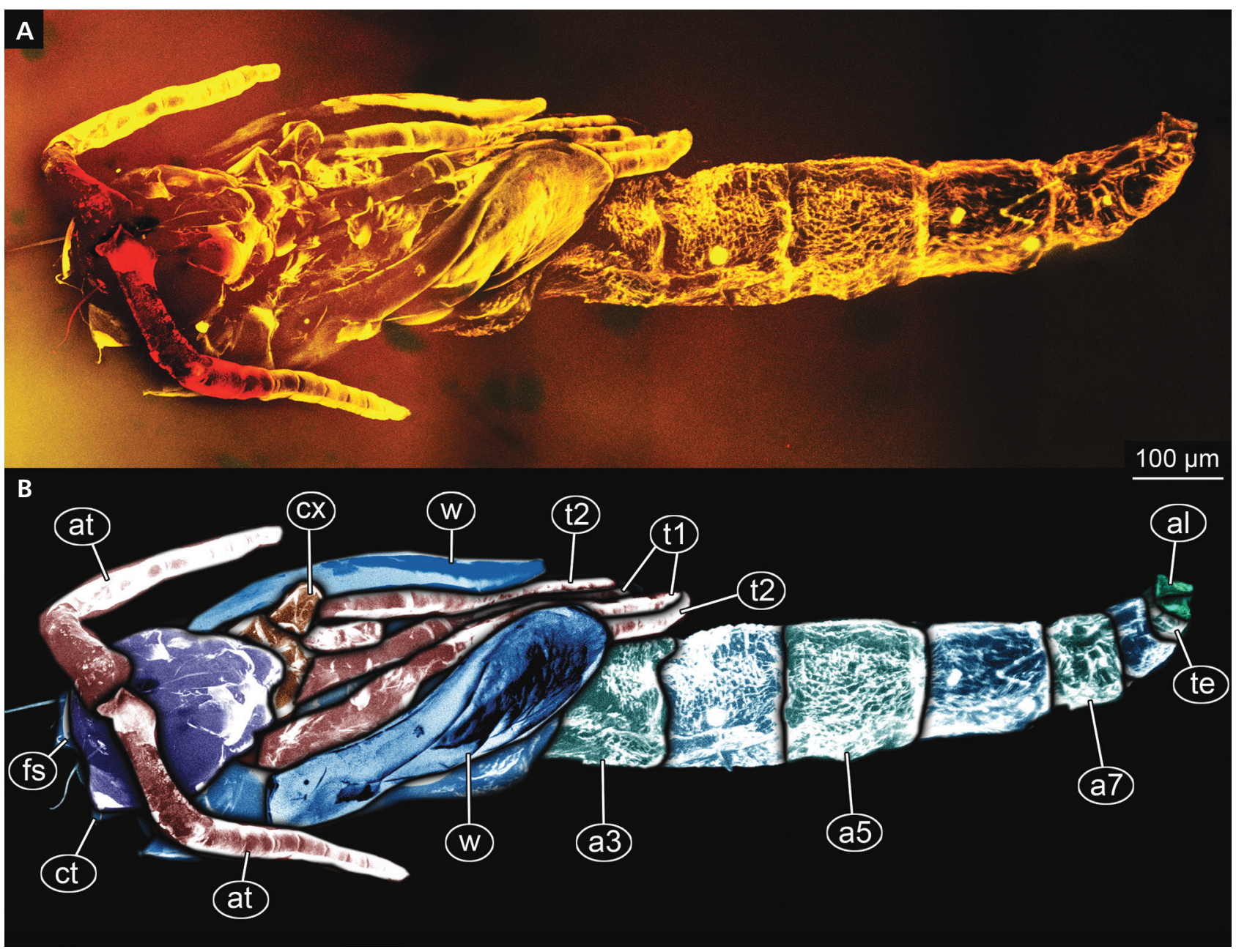

Figure 8. Pupa cf. Bryophaenocladius; A - body of the pupa; B - body of the pupa with the marked structures. Abbreviations: at - antenna; al - anal lobes; cx - coxa; ct - cephalic tubercle; fs - frontal setae; $\mathrm{t} 1$ - foreleg sheaths; $\mathrm{t} 2$ - midleg sheaths; $\mathrm{a} 3-\mathrm{a} 7$ - abdominal segments; w - wing. Figure 7A, B reproduced from Andersen, T., Baranov, V., Goral, T., Langton, P., Perkovsky, E. \& Sykes, D. First record of a Chironomidae pupa in amber. Geobios 2015; 48(4): 281-286. Copyright (C) 2015, Elsevier Masson SAS. All rights reserved.

pupa in the solid substrates) and extremely shortened anal lobes of abdominal segment 9 (anal lobes are used for swimming by aquatic pupae, and thus obsolete in terrestrial environments; Wiederholm 1986; Fig. 8A, B).

A pupa with these characteristics was found in Rovno Eocenic amber, contemporary to Baltic amber (Andersen et al. 2013; Fig. 8A, B). This pupa, a representative of Orthocladiinae, has unmistakable traits of a terrestrial life, such as the absence of the thoracic horns or short anal lobes. The morphology of the pupa most closely resembles pupae of modern representatives of Bryophaenocladius, but differs from the latter in presence of the frontal setae (Fig. 8B). Therefore, this pupa does not fit exactly into the diagnosis of Bryophaenocladius sensu Makarchenko $\&$ Makarchenko (2006). It nevertheless fits very well into the overall morphotype of this group.

Adult males of Bryophaenocladius (Fig. 9A, B) are characterized by the erect acrostichal setae starting close to antepronotum, wings without macrotrichia, but bearing visible microtrichial ornamentation, and a broadbased anal point with a translucent apical part. Some representatives of the morphotype also have a digitiform projection of the 3D element of the maxillary palp (Makarchenko \& Makarchenko 2006).

In addition to the immature stages of the Bryophaenocladius morphotype, fossil adults of Bryophaenocladius are also known from three amber deposits: Bryophaenocladius circumclusus Seredszus \& Wichard, 2007, B. beuki Baranov, Andersen \& Hagenlund, 2015 - both from Eocene Baltic amber, and a so far unnamed species from Miocene New Zealand amber (Schmidt et al. 2018).

All the fossil males of Bryophaenocladius have wings with strong microtrichial ornamentation, a translucent tip of the anal point, as well as strong acroastichal setae and in some cases (the yet unnamed species from NZ) a strong apical projection of the third element of the 
maxillary palp (Seredszus \& Wichard 2007, Baranov et al. 2015a, Schmidt et al. 2018).

For the first time we have now a rather complete reconstructed ontogenetic series, at least concerning life phases, available for a fossil representative of Diptera as well preserved specimens from amber. Earlier workers (i.e. Kalugina \& Kovalev 1985) made use of Lagerstätten of aquatic insects to associate the life stages of fossil representatives of Diptera (i.e. Chaoboridae) in a reconstructed ontogenetic series (Kalugina \& Kovalev 1985). Howeverer, due to the poor preservations of the aforementioned compression fossils, many crucial characters are obscured or absent, which makes ontogenetic associations quite tentative (Kalugina \& Kovalev 1985, Borkent 2012). The development of new imaging technologies and the accumulation of fossil material, has led to increasingly frequent description of more complete ontogenetic series, especially in the marine animals from the sedimentary Laggerstätten (e.g. Haug \& Haug 2016, Haug et al. 2018).

\section{The case of bradytely in terrestrial Chironomidae}

The new record of a chironomid larva from Baltic amber presents another case of a bradytely, or evolutionary stasis, in the lineage of Chironomidae. Eocene and extant representatives of the Bryophaenocladius morphotype are extremely similar (Figs 3A-D; 5A-D). Bradytely seems relatively uncommon among Chironomidae across the Cretaceous-Paleogene boundary (Kalugina 1974, Baranov et al. 2015b). The Cretaceous Terrestrial Revolution's (CTR) impact on freshwater and terrestrial ecosystems might be a reason for the lack of Cretaceous-type species of Chironomidae after the K-Pg Event (Kalugina 1974, Baranov et al. 2015b). Bradytely seems relatively common within Diptera from the Eocene onwards and in Chironomidae in particular. Many of the modern-day principle morphotypes ( $\approx$ genera) of Chironomidae are already known from the early Eocene onwards (Seredszus \& Wichard 2007). This prevalence of the morphotypes enables Chironomidae-based palaeoclimate and habitat inference (Gründ 2006, Seredszus \& Wichard 2007, Zelentsov et al. 2012, Baranov et al. 2015b).

The new reconstruction of the ontogenetic series presented here provides an important clue for understanding of the evolution of lineages with terrestrial larvae within Chironomidae (Andersen et al. 2015). Adult representatives of lineages within Chironomidae that are characterised by terrestrial larvae are present in most of amber deposits known to date (Sakhalin, Rovno, Baltic, Cambay, Fushun; Zelentsov et al. 2012, Baranov et al. 2015b, Gilka et al. 2016). Some deposits (Rovno amber in particular) have a high proportion of the nonbiting midges that should possess morphotypes with terrestrial larvae, based on phylogenetic reasoning, among the identified fauna (Zelentsov et al. 2012). Continuous presence of such morphotypes in the Eocene amber forest is indicative of the abundance of the terrestrial mosses and other moisture habitats in the amber forests of the Eocene (Zelentsov et al. 2012, Andersen et al. 2015).

Despite the tight association of Chironomidae with terrestrial larvae with mosses, most of their habitats are located within forests or grasslands (Delettre 2000, Frouz 2010). Probably moss carpets per se were not providing suitable habitats for Chironomidae with terrestrial larvae. It seems that the CTR (Cretaceous Terrestrial Revolution) and the related emergence of the deciduous forests and grassland were a pivotal moment in the development of the terrestrial larval morphotype within Chironomidae, which has appeared in geological records in the Paleogene (Baranov et al. 2015b). Probably, an increased amount of organic detritus from the deciduous trees and seasonal grasses provided these larvae with suitable nutrition in the moss carpets (Kalugina 1974).

Bryophaenocladius firstly appeared in fossil records in the Priabonian (ca. 38 mya) and has since exhibited little changes in its morphotype (Andersen et al. 2015). The main reason for this is most probably the relative stability of the mossy habitats in the forest during Paleogene and Neogene (Glime 2017). Such habitats even become a refugium for numerous lineages of Insecta that exhibit bradytely (Yamamoto et al. 2017).

One example of a hygrophilous terrestrial insect with an extremely high degree of morphological traits conservation is the beetle Attagenus (Aethriostoma) turonianensis from late Cretaceous New Jersey amber, a species of Dermestidae, which was interpreted as an ingroup of Attagenus (Peris \& Háva 2016). Fossil specimens of another beetle Micromalthus debilis LeConte, 1878 (Micromalthidae) from Dominican amber, could not be distinguished from the extant specimens and were hence interpreted as a long-term surviving species (Hörnschemeyer et al. 2010).

Therefore, bradytely within Insecta in the moist terrestrial habitats seems to be a relatively common occurrence, indicating the importance of this type of habitats as an insect refugium (Hörnschemeyer et al. 2010).

\section{Conclusions}

Reconstruction of a rather complete ontogenetic sequence of the Bryophaenocladius morphotype once again emphasises that fossil insects are much more than just dead males. Although for taxonomic reasons adult males are in the centre of most studies, relevant information is to 

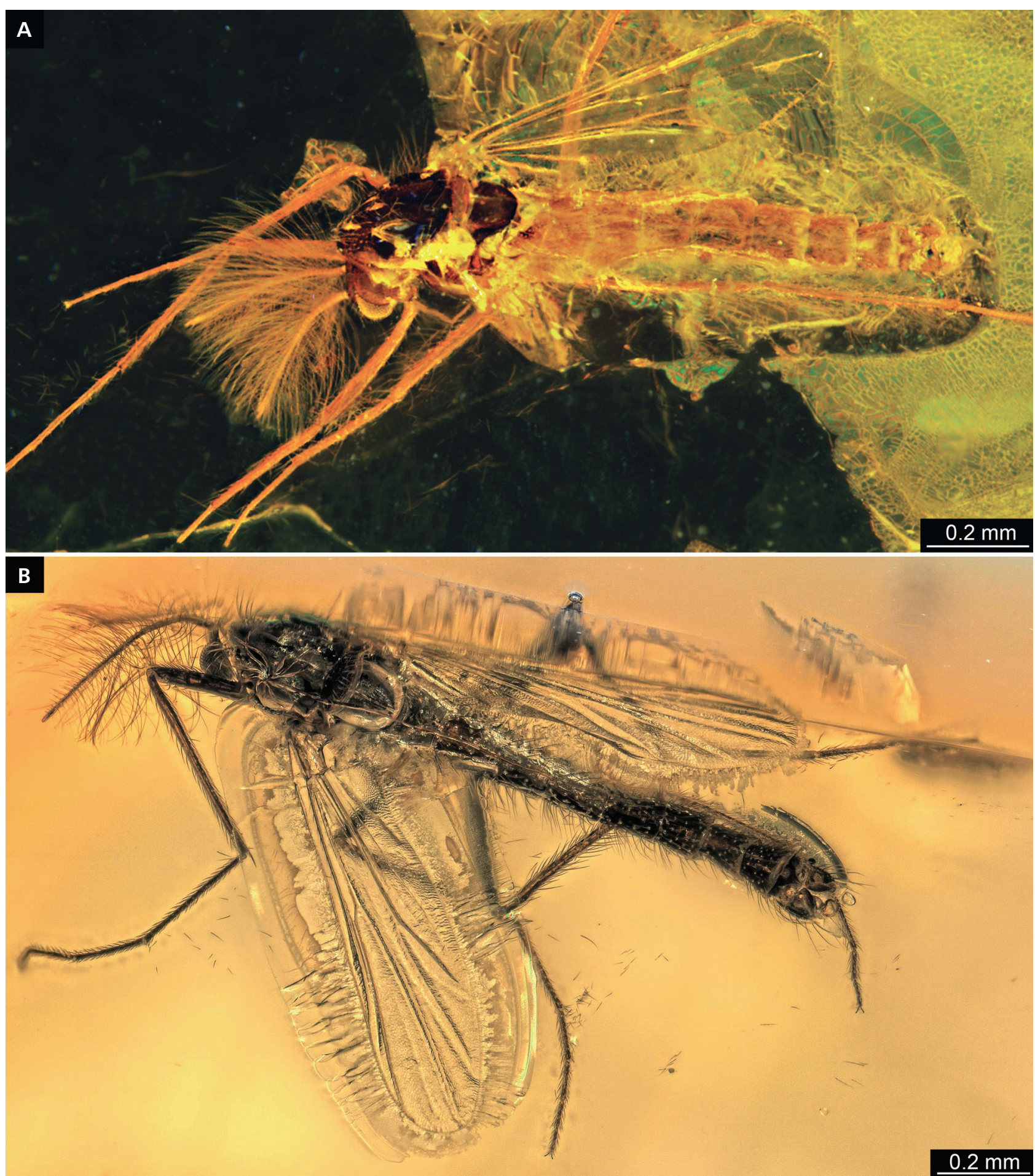

Figure 9. Adult males of Bryophaenocladius. • A - Bryophaenocladius beuki (holotype, no. 1165135055). B - Bryophaenocladius circumclusus (holotype). Scale bar $=0.5 \mathrm{~mm}$. Figure 8A is re-used with permission of Norwegian Entomological Journal from Baranov et al. (2015a).

be gained also from the other fossils. Information of fossils is not limited to mere taxonomic descriptions or calibration of the phylogenetic nodes. Studies of fossil forms of Insecta allow us to reconstruct the changes of individual development of extinct organisms. In particular, studying immature stages of Cretaceous representatives of Insecta, and their comparison with counterparts from the Palaeogene allows us to decipher the impact of the end-Cretaceous Extinction Event and the Cretaceous Terrestrial Revolution on the ecosystems. 
Current reconstructions of the Bryophaenocladius morphotype are suggesting strong stability of the moist terrestrial habitats occupied by representatives of Chironomidae with terrestrial larvae in the Palaeogene and Neogene, and their continued importance for the survival of the relic lineages within Insecta. On top of that, the new record of a fossil larva from the Baltic amber enables us to better understand the evolution of the ontogeny within Chironomidae.

\section{Acknowledgements}

Senior author and JTH are kindly funded by the Volkswagen Foundation (Lichtenberg professorship to JTH). Senior author is grateful to M. Spies (ZSM Munich) for his invaluable help with collection of ZSM as well as help with the literature. Authors are grateful to Øivind Gammelmo (Norwegian Journal of Entomology) and legal department of Elsevier Masson for kind permission to reuse figures from VB's previous works. Thanks to all people providing free software. We are grateful to the editor as well as to the reviewers, Trond Andersen and Wilfried Wichard, for their efforts in improving this manuscript.

\section{References}

Andersen, T., Baranov, V., Goral, T., Langton, P., Perkovsky, E. \& Sykes, D. 2015. First record of a Chironomidae pupa in amber. Geobios 48(4), 281-286.

DOI 10.1016/j.geobios.2015.06.004

Andersen, T., Baranov, V., Hagenlund, L.K., Ivkovic, M., Kvifte, G.M. \& Pavlek, M. 2016. Blind flight? A new troglobiotic orthoclad (Diptera, Chironomidae) from the Lukina Jama-Trojama Cave in Croatia. PLoS ONE 11(4), 15 pp., 5 supp. files. DOI 10.1371/journal.pone.0152884

Andersen, T., Słther, O.A., Cranston, P.S. \& Epler, J.H. 2013. The larvae of Orthocladiinae (Diptera: Chironomidae) of the Holarctic Region - 9. Keys and diagnoses, 189-385. In Andersen, T., Cranston, P.S. \& Epler, J.H. (eds) Chironomidae of the Holarctic Region: Keys and diagnoses, Part 1: Larvae. Insect Systematics and Evolution Supplement 66.

Ashe, P. \& O'Connor, J.P. 2012. A World Catalogue of Chironomidae (Diptera). Part 2. Orthocladiinae (Section $A \&$ Section B). xvi +968 pp. Irish Biogeographical Society $\&$ National Museum of Ireland, Dublin.

Baranov, V., Andersen, T. \& Hagenlund, L.K. 2015a. A new species of Bryophaenocladius Thienemann, 1934 (Diptera, Chironomidae, Orthocladiinae) from Baltic amber. Norwegian Journal of Entomology 62(1), 53-56.

Baranov, V., Andersen, T. \& Perkovsky, E.E. 2015b. Orthoclads from Eocene Amber from Sakhalin (Diptera: Chironomidae, Orthocladiinae). Insects Systematic Evolution 46(4), 359-378. DOI 10.1163/1876312X-45032122

Borkent, A. 2012. The pupae of Culicomorpha - Morphology and a new phylogenetic tree. Zootaxa 3396, 1-98.
Cranston, P.S. 1995. Systematics, 31-61. In Armitage, P.D., Cranston, P.S. \& Pinder, L.C.V. (eds) The Chironomidae. Biology and ecology of non-biting midges. Chapman and Hall, London, etc.

DeLetTRE, Y.R. 2005. Short-range spatial patterning of terrestrial Chironomidae (Insecta: Diptera) and farmland heterogeneity. Pedobiologia 49, 15-27. DOI 10.1016/j.pedobi.2004.06.010

Ekrem, T., Ashe, P., Andersen, T. \& Stur, E. 2017. Chironomidae (non-biting midges), 813-863. In Kirk-Spriggs, A.H. \& Sinclair, B.J. (eds) Manual of Afrotropical Diptera. Volume 2: Nematocerous Diptera and lower Brachycera. Suricata 5. South African National Biodiversity Institute, Pretoria.

FERrington, L.C. JR. 2008. Global diversity of non-biting midges (Chironomidae; Insecta-Diptera) in freshwater. Hydrobiologia 595, 447-455. DOI 10.1007/s10750-007-9130-1

Frouz, J. 1997. The effect of vegetational patterns on oviposition habitat preference: a driving mechanism in terrestrial chironomid (Diptera: Chironomidae) succession? Researches on Population Ecology 39, 207-213. DOI 10.1007/BF02765267

Frouz, J. 2010. Terrestrial chironomids in disturbed habitats, 41-44. In Ferrington, L.C. JR. (ed.) Proceedings of the XV International Symposium on Chironomidae. Chironomidae Research Group, University of Minnesota, Saint Paul, Minnesota.

Gilka, W., Zakrzewska, M., Baranov, V., Wang, B. \& Stebner, F. 2016. The first fossil record of Nandeva Wiedenbrug, Reiss \& Fittkau (Diptera: Chironomidae) in early Eocene Fushun amber from China. Alcheringa Australasian Journal of Palaeontology 40(3), 390-397.

DOI 10.1080/03115518.2016.1145529

Glime, J.M. 2017. Aquatic insects: Biology. Chapter 11-1. In Glime, J.M.(ed.) Bryophyte Ecology. Volume 2. Bryological Interaction.

http://digitalcommons.mtu.edu/bryophyte-ecology2/

Goetghebuer, M. 1938. Quelques Chironomides nouveaux de 1'Europe. Bulletin et Annales de la Societe Entomologique de Belgique 78(11), 453-464.

GRÜND, M. 2006. Chironomidae (Diptera) in Dominican amber as indicators for ecosystem stability in the Caribbean. Palaeogeography, Palaeoclimatology, Palaeoecology 241, 410-416. DOI 10.1016/j.palaeo.2006.04.005

Haug, C., Shannon, K.R., Nyborg, T. \& Vega, F.J. 2013 a. Isolated mantis shrimp dactyli from the Pliocene of North Carolina and their bearing on the history of Stomatopoda. Bolétin de la Sociedad Geológica Mexicana 65, 273-284. DOI 10.18268/BSGM2013v65n2a9

Haug, J.T. \& HaUG, C. 2016. "Intermetamorphic" developmental stages in 150 million-year-old achelatan lobsters - The case of the species tenera Oppel, 1862. Arthropod Structure \& Development 45, 108-121. DOI 10.1016/j.asd.2015.10.001

Haug, J.T., Haug, C. \& Ehrlich, M. 2008. First fossil stomatopod larva (Arthropoda: Crustacea) and a new way of documenting Solnhofen fossils (Upper Jurassic, Southern Germany). Palaeodiversity 1, 103-109.

Haug, J.T., Müller, P. \& Haug, C. 2018. The ride of the parasite: a 100-million-year old mantis lacewing larva captured while mounting its spider host. Zoological letters 4(31), 1-8. 
Haug, J.T., Müller, C.H.G. \& SombKe, A. 2013b. A centipede nymph in Baltic amber and a new approach to document amber fossils. Organisms Diversity \& Evolution 13, 425-432. DOI 10.1007/s13127-013-0129-3

Haug, J.T., Haug, C., Kutschera, V., Mayer, G., Maas, A., Liebau, S., Castellani, C., Wolfram, U., Clarkson, E.N.K. \& WALOSZEK, D. 2011. Autofluorescence imaging, an excellent tool for comparative morphology. Journal of Microscopy 244, 259-272. DOI 10.1111/j.1365-2818.2011.03534.x

Hoffeins, H.W. 2001. On the preparation and conservation of amber inclusions in artificial resin. Polskie pismo entomologiczne 10(2), 381-392.

Hoffeins, C. \& Hoffeins, H.W. 2003. Untersuchungen über die Häufigkeit von Inklusen in Baltischem und Bitterfelder Bernstein (Tertiär, Eozän) aus unselektierten Aufsammlungen unter besonderer Berücksichtigung der Ordnung Diptera. Studia dipterologica 10(2), 381-392.

Hörnschemeyer, T., Wedmann, S. \& Poinar, G. 2010. How long can insect species exist? Evidence from extant and fossil Micromalthus beetles (Insecta: Coleoptera). Zoological Journal of the Linnean Society 158(2), 300-311. DOI 10.1111/j.1096-3642.2009.00549.x

Kalugina, N.S. 1974. Change in the subfamily composition of chironomids (Diptera, Chironomidae) as an indicator of possible eutrophication of bodies of water during the late Mesozoic. Journal of the Moscow Naturalist's Society 79, 45-56.

Kalugina, N.S. 1985. Infraorder Culicomorpha, 63-113. In Kalugina, N.S. \& Kovalev, N.S. (eds) Dvukrylye Yury Sibiri [Insecta Diptera of the Jurassic in Siberia]. Izdatelstvo Akademii nauk SSSR, Paleontologicheskii Institut, Moskovskogo Obshchestva Ispytatelej Prirody, Moscow. [in Russian]

Kieffer, J.J. in Tienemann, A. \& Kieffer, J.J. 1916. Schwedische Chironomiden. Archiv für Hydrobiologie Supplement 2(3), 483-554.

Kirk-Spriggs, A. \& Muller, B. 2017. Biogeography of Diptera, 203-238. In Kirk-Spriggs, A.H. \& Sinclair, B.J. (eds) Manual of Afrotropical Diptera. Volume 1. Introductory chapters and keys to Diptera families. Suricata 4. SANBI Graphics and Editing, Pretoria.

Komnick, H. \& Wichard, W. 1975. Vergleichende Cytologie der Analpapillen, Abdominalschläuche und Tracheenkiemen aquatischer Mückenlarven (Diptera, Nematocera). Zeitschrift für Morphologie der Tiere 81, 323-341.

DOI 10.1007/BF00298491

Langton, P.H. 1995. The pupa and events leading to eclosion, 169-193. In Armitage, P.D., Cranston, P.S. \& Pinder, L.C.V. (eds) The Chironomidae. Biology and ecology of non-biting midges. Chapman and Hall, London.

LeConte, J.L. 1878. The Coleoptera of Michigan. 1. Descriptions of new species. Proceedings of the American Philosophical Society, Philadelphia 17, 593-648.
Makarchenko, E.A. \& Makarchenko, M.A. 2006. Podsemeistvo Orthocladiinae. [Subfamily Orthocladiinae], 280-372, 482-530, 623-671. In Lelel, A.S. (ed.) Diptera and Aphaniptera. Opredelitel' Nasekomykh Dal'nego Vostoka Rossii 6.

Marshall, S.A. 2012. Flies: the natural history \& diversity of Diptera . 616 pp. Firefly Books, Richmond Hill, Ontario.

Peris, D. \& Háva, J. 2016. New species from Late Cretaceous New Jersey amber and stasis in subfamily Attageninae (Insecta: Coleoptera: Dermestidae). Journal of Paleontology 90(3), 491-498. DOI 10.1017/jpa.2016.51

S ology (Diptera: Chironomidae). Entomologica Scandinavica 14, 1-51.

Schmidt, A.R., Kaulfuss, U., Bannister, J.M., Baranov, V., Beimforde, C., Bleile, N., Borkent, A., Busch, A., Conran, J.G., Engel, M.S., Harvey, M., Kennedy, E.M., Kerr, P.H., Kettunen, E., Philie Kiecksee, A., Lengeling, F., Lindqvist, J.K., Maraun, M., Mildenhall, D.C., Perrichot, V., RikKinen, J., Sadowski, E.-M., Seyfullah, L.J., Stebner, F., Szwedo, J., Ulbrich, P. \& Lee, D.E. 2018. Amber inclusions from New Zealand. Gondwana Research 56, 135-146. DOI 10.1016/j.gr.2017.12.003

Seredszus, F. \& Wichard, W. 2007. Fossil chironomids (Insecta, Diptera) in Baltic amber. Palaeontographica, Abteilung A 279, 49-91. DOI 10.1127/pala/279/2007/49

Thienemann, A. 1934. Chironomiden-Metamorphosen. VIII. «Phaenocladius». Encyclopedie Entomologique, B-II, Diptera 7, 29-46.

Weitschat, W. \& Wichard, W. 2010. Baltic Amber, 80-115. In Penney, D. (ed.) Biodiversity of fossils in Amber from the major world deposits. Siri Scientific Press, Manchester.

Wichard, W., Arens, W. \& Eisenbeis, G. 2002. Biological Atlas of Aquatic Insects. 339 pp. Apollo Books, Stentrup, Denmark.

Wichard, W., GröHn, C. \& Seredszus, F. 2009. Wasserinsekten im Baltischen Bernstein. Aquatic Insects in Baltic Amber. 335 pp. Verlag Kessel, Remagen-Oberwinter.

Wiederholm, T. (ed.) 1983. Chironomidae of the Holarctic region. Keys and diagnoses. Part I: Larvae. Entomologica scandinavica Supplement 19, 1-457.

Wiederholm, T. (ed.) 1986. Chironomidae of the Holarctic region. Keys and diagnoses. Part II: Pupae. Entomologica scandinavica Supplement 28, 1-482.

Yamamoto, S., Takahashi, Y. \& Parker, J. 2017. Evolutionary stasis in enigmatic jacobsoniid beetles. Gondwana Research 45, 275-281. DOI 10.1016/j.gr.2016.12.008

Zelentsov, N.I., Baranov, V.A., Perkovsky, E.E. \& Shobanov, N.A. 2012. First records on[sic] non-biting midges (Diptera: Chironomidae) from the Rovno amber. Russian Entomological Journal 21(1), 79-87.

DOI 10.15298/rusentj.21.1.10 